\title{
IMPLICATIONS OF HOST WEEVIL CIRCADIAN ACTIVITY FOR PARASITISM BY MICROCTONUS AETHIOPOIDES (HYMENOPTERA: BRACONIDAE)
}

\author{
K.M. COUCH ${ }^{1}$, A.S. CRESSWELL ${ }^{1}$, B.I.P. BARRATT ${ }^{2}$ \\ and A.A. EVANS ${ }^{2}$ \\ ${ }^{1}$ Department of Zoology, University of Otago, P.O. Box 56, Dunedin \\ ${ }^{2}$ AgResearch, Invermay Agricultural Centre, Private Bag 50034, Mosgiel
}

\begin{abstract}
Previous studies have suggested that the braconid parasitoid Microctonus aethiopoides Loan oviposits in its target host Sitona discoideus (Kuschel) primarily during light periods, and therefore, diurnally active non-target weevils may be more susceptible to parasitism than nocturnally active weevils. A laboratory investigation was carried out to measure the circadian feeding and oviposition activity patterns of three known non-target hosts of $M$. aethiopoides. M. aethiopoides was also exposed to Listronotus bonariensis Gyllenhal, a crepuscularly active weevil, in light or dark periods or continuously over a 16 hour light: 8 hour dark photoperiod. Feeding by two native species increased during the light period, while that of the introduced Rhinocyllus conicus (Froelich) remained relatively constant throughout the light-dark cycle. Neither of the native species showed a consistent circadian oviposition pattern. $R$. conicus laid more eggs during light than dark periods. $M$. aethiopoides oviposited in $L$. bonariensis equally during light and dark periods.
\end{abstract}

Keywords: Microctonus aethiopoides, non-target hosts, circadian rhythms, host activity

\section{INTRODUCTION}

Microctonus aethiopoides Loan (Hymenoptera: Braconidae) is a solitary endoparasitoid introduced to New Zealand in 1982 to control Sitona discoideus (Kuschel), an exotic pest of lucerne (Medicago sativa L.). However, M. aethiopoides has since been found to parasitise 13 non-target weevil species in the field (Barrattet al. 1997). Ten of these are native species, and one, Rhinocyllus conicus (Froelich), is an introduced biological control agent of nodding thistle, Carduus nutans L. (Ferguson et al. 1994).R. conicus and the native weevils,Irenimus aemulator (Broun) andNicaeana cervina Broun are present in grassland where M. aethiopoides is active (Barratt et al. 1995) and also co-occurs with $S$. discoideus in lucerne (Ferguson et al. 1994).

Armstrong et al. (1996) suggested that M. aethiopoides oviposition activity corresponded to the diurnal activity pattern of its target host, $S$. discoideus.

The objective of this investigation was to examine the activity patterns of I. aemulator, $N$. cervina and $R$. conicus using feeding and oviposition as indicators of activity and to test the hypothesis that $M$. aethiopoides is diurnal.

\section{Insect collection and rearing}

\section{METHODS}

Adult weevils were field collected from pasture in the Strath Taieri and Kyeburn, Otago, during November 1996. R. conicus were hand-picked from nodding thistle plants, and I. aemulator and $N$. cervina were collected using a modified Homelite HB $390 \mathrm{~V}$ blower-vac. L. bonariensis were collected from pasture near Lincoln, Canterbury in January 1997. M. aethiopoides were reared from $S$. discoideus.

The weevils were held for $14-21$ days in a laboratory at $20 \pm 2{ }^{\circ} \mathrm{C}$ with a $16: 8$ hour

Proc. 50th N.Z. Plant Protection Conf. 1997: 227-231 
photoperiod to purge them of any parasitoids. In all cases, weevils were housed in plastic cages $160 \times 180 \times 75 \mathrm{~mm}$ deep with a plastic coated mesh floor inserted into another similar cage with textured absorbent paper towel covering the floor.

The native weevils were supplied with lucerne ((Medicago sativaL.) cv. 'Wairau'), ryegrass (((Lolium perenne $\mathrm{x}$ L. multiflorum $) \times$ L. perenne $) \mathrm{cv}$. 'Manawa') and pollen collected from a hive trap. $R$. conicus received nodding thistle leaves and flower heads, and $L$. bonariensis received ryegrass and pollen, as above. Water was supplied on moistened cotton wool dental rolls.

\section{Experiment 1}

Two rooms, at $20 \pm 2^{\circ} \mathrm{C}$, were set up with a 16 hour light: 8 hour dark photoperiod. For convenience the photoperiods of the two rooms were set out of phase with each other, so that one room was dark from 08:00 to 16:00 hours, and the other from 16:30 to 00:30 hours. Twenty individuals of either $I$. aemulator ( 6 replicates), $N$. cervina ( 6 replicates) or $R$. conicus (10 replicates) were placed in cages as above, and were left for five days to acclimatise to the light regime used in the experiments. The replicates were divided evenly between the two rooms for each species.

Four-hourly assessments of $I$. aemulator and $N$. cervina were made over 24 hour periods every third day on six occasions. Similar assessments for $R$. conicus were made every fifth day on three occasions. At each assessment time, the food and dental rolls were changed, eggs counted and removed, and the amount of each plant species consumed was measured by placing the leaf material over $1 \mathrm{~mm}$ graph paper and counting the number of squares and part squares removed. Assessments during dark periods were carried out under red light. Dead weevils were removed and preserved in $70 \%$ ethanol. These as well as weevils surviving the experiment were dissected to determine their gender.

\section{Experiment 2}

Fifteen groups of $20 \mathrm{~L}$. bonariensiseach, were placed in cages and allocated to one of three treatments:

1. 48 hours continuous exposure to three M. aethiopoides females (two cycles of 16L:8D)

2. 3 x16 hour periods of exposure to three $M$. aethiopoides females during light periods only

3. 6 × 8 hour periods of exposure to three M. aethiopoides females during dark periods only

Between periods of exposure in treatments 2 and 3, parasitoids were held in plastic vials with gauze lids containing honey-soaked dental rolls and kept at the same photoperiod as the weevils. The same parasitoids were reintroduced to each cage for each exposure period. Parasitoids that died during the experiment were replaced with others that had been maintained in the same photoperiod in holding cages.

Following exposure to the parasitoids, the weevils were maintained for three weeks until no further parasitoids had emerged for 48 hours. Subsequently all weevils were dissected to record any further parasitism.

\section{Data analysis}

Feeding and oviposition data were analysed using a parsimonious generalised linear model (Nelder and Wedderburn 1972). The oviposition data for the $N$. cervina and $I$. aemulator were transformed using a natural logarithm before analysis. The analyses were adjusted for the covariates; 'survival' and 'the number of females present'. Parasitism data were analysed using a generalised linear model, with a binomial distribution and logit link functions (Dobson 1990).

\section{Experiment 1}

\section{RESULTS}

No significant difference in feeding or oviposition was found between the two rooms used for the experiment, but there was a significant reduction in feeding activity between successive days over which the measurements were taken $(\mathrm{P}<0.05)$.

A significant increase $(\mathrm{P}<0.05)$ in feeding activity was observed during the light 
period for both N. cervina and I. aemulator (Fig. 1A). R.conicus fed at a constant level throughout the 24 hour periods.

There were no significant differences in oviposition between light and dark periods for any of the species during the four-hourly sampling intervals (Fig. 1B). However, oviposition by $N$. cervina and I. aemulator tended to increase during the dark period. Experiment 2

There was no significant difference in parasitism levels between the three treatments
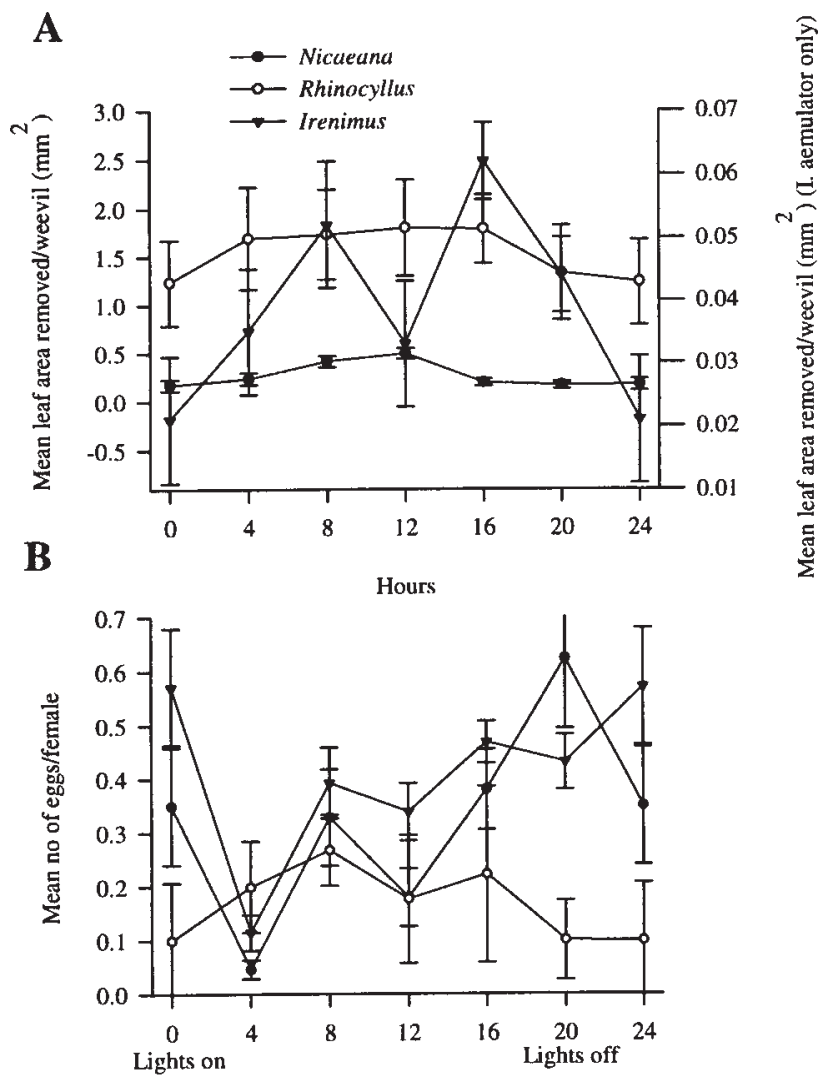

Hours

FIGURE 1: Mean leaf area removed by feeding (1A) and number of eggs laid (1B) inNicaeana cervina, Irenimus aemulator andRhinocyllus conicus measured every 4 hours per weevil. Error bars represent \pm 1 SE.

(Table 1). Mortality was higher in the parasitoids used in treatments two (33.3\%) and three $(6.7 \%)$, than in treatment one $(0 \%)$.

TABLE 1: Parasitism(\%) ofListronotus bonariensis byMicroctonus aethiopoides in three exposure regimes. 
Parasitoid exposure

48 continuous hours

$3 \times 16$ hour light periods

$6 \times 8$ hour dark periods
Total parasitism $(\%) \pm$ SEM
$16 \pm 3.7$

$17 \pm 3.8$

$15 \pm 3.6$

\section{DISCUSSION}

Bremner (1988) described Nicaeana and Irenimus species as opportunists in relation to their seasonal and diurnal activity patterns, becoming active in the field whenever temperature conditions were favorable. He found that native weevils were active day and night during summer when temperatures remained above $6^{\circ} \mathrm{C}$. These experiments were carried out under temperature conditions well above the lower limit for activity of $I$. aemulator and $N$. cervina, so weevil activity during both light and dark periods would be expected, and this appeared to be the case. I. aemulator and $R$. conicus feeding did not follow a strictly diurnal or nocturnal pattern.

The pattern of oviposition was highly variable in all three species, and in the case of the native species, clear patterns were obscured by their habit of ovipositing eggs in batches. However, all three species showed reduced egg production in the middle of the light period, which would correspond with the hottest part of the day in the field. This is possibly an adaptation to avoid desiccation of the eggs before they are fully hardened.

All three species are active during the day, which could explain their susceptibility to parasitism by $M$. aethiopoides in the field. Ferguson et al. (1994) suggested that parasitising non-target weevils may provide a 'refuge' and help M. aethiopoides to survive between generations of its target host.

Armstrong et al. (1996) found that M. aethiopoides oviposited in S. discoideus, primarily during light periods. However, when exposed to L. bonariensis, which feeds during dark periods, but oviposits during the night and day, M. aethiopoides oviposition occurred equally during light and dark periods. This suggests that the parasitoid may respond to cues from host activity rather than an endogenous circadian rhythm of its own. Observations by Loan and Holdaway (1961) suggested that $M$. aethiopoides was reliant on host movement for successful stalking and oviposition. The results of this study indicate that $M$. aethiopoides can successfully parasitise hosts throughout the 24 hour period.

In contrast, $M$. hyperodae (an introduced biological control agent for L. bonariensis (Goldson et al. 1984)) laid fewer eggs within its host during the day than the night, possibly indicating a more distinct rhythmicity in stalking activity (Armstrong et al. 1996). Several hymenopteran egg and larval parasitoids have distinct circadian rhythms of locomotor activity independent of host activity but this varies with species, sex and strain (Fleuryetal. 1991). AsM. aethiopoides and M. hyperodae evolved in the presence of different host fauna in Europe and South America respectively (Loan and Holdaway 1961; Goldson et al. 1992), differences in their behavioural repertoires might be expected. However, if $M$. aethiopoides is potentially active throughout the 24 hour period, a wider range of potential hosts might be available to it than for $M$. hyperodae, which might be more restricted to nocturnally active weevils.

\section{ACKNOWLEDGEMENTS}

The senior author would like to thank AgResearch for a summer studentship award during which the research on native weevil activity and parasitoid oviposition was conducted. The authors would also like to thank Peter Johnstone for statistical analysis. Ann Cresswell would like to thank Robert Poulin, Colin Ferguson and Craig Phillips for their supervision and suggestions.

\section{REFERENCES}

Armstrong, S.M., Barratt, B.I.P. and Evans, A.A., 1996. Circadian pattern of oviposition in the parasitoids Microctonus aethiopoides Loan and M. hyperodae Loan (Hymenoptera: Braconidae), in relation to host activity.Proc. 49th N.Z. Plant Prot. 
Conf:: 280-284.

Barratt, B.I.P., Evans, A.A. and Ferguson, C.M., 1995. Circadian patterns of oviposition and feeding in Listronotus bonariensis (Kuschel) (Coleoptera: Curculionidae) in the laboratory. Proc. 48th N. Z. Plant Prot Conf:: 219-223.

Barratt, B.I.P., Evans, A.A., Ferguson, C.M., Barker, G.M., McNeill, M.R. and Phillips, C.B., 1997. Laboratory non-target host range of the introduced parasitoids Microctonus aethiopoides andMicroctonus hyperodae (Hymenoptera: Braconidae) compared with field parasitism in New Zealand. Environ. Entomol. 26(3): 694-702.

Bremner, G., 1988. Ecological studies of the insect fauna of the East Otago Plateau. PhD Thesis, University of Otago, Dunedin, N.Z., 211p.

Dobson, A.J., 1990. An Introduction to Generalised Linear Models. Chapman and Hall.

Ferguson, C.M., Roberts, G.M., Barratt, B.I.P. and Evans, A.A., 1994. The distribution of the parasitoid Microctonus aethiopoides Loan (Hymenoptera: Braconidae) in southern South Island Sitona discoideus Gyllenhal (Coleoptera: Curculionidae) populations. Proc. 47th N.Z. Plant Prot. Conf: :261-265.

Fleury, F., Pompanon, F., Mimouni, F., Chassain, C., Fouillet, P., Allemand, R. and Bouletreau, M., 1991. Daily rhythmicity of locomotor activity in adult hymenopteran parasitoids. Fourth European Workshop - Perugia 3-5 April, 1991.REDIA, 74(3): 287-293.

Goldson, S.L., Frampton, E.R., Barratt, B.I.P. and Ferguson, C.M., 1984. The seasonal biology of Sitona discoideus Gyllenhal (Coleoptera: Curculionidae), an introduced pest of New Zealand lucerne. Bull. Ent. Res. 74: 249-259.

Goldson, S.L., McNeill, M.R., Phillips, C.B. and Proffitt, J.R., 1992. Host specificity testing and suitability of the parasitoid Microctonus hyperodae as a biological control agent of Listronotus bonariensis in New Zealand. Entomophaga 37: 483-498.

Loan, C.C. and Holdaway, F.G., 1961. Microctonus aethiops (Nees) and Perilitus rutilus (Nees) (Hymenoptera: Braconidae), European parasites of Sitona weevils (Coleoptera: Curculionidae). Can. Entomol. 93: 1057-1079.

Nelder, J.A. and Wedderburn, R.M.W., 1972. Generalised Linear Models.J. Roy. Stat. Soc. A 135: 370-384. 